\title{
Case Report \\ Giant Condyloma Acuminatum of Vulva in an HIV-Infected Woman
}

\author{
Athanase Lilungulu, ${ }^{1}$ Bonaventura C. T. Mpondo, ${ }^{2}$ Abdallah Mlwati, ${ }^{2}$ Dismas Matovelo, ${ }^{3}$ \\ Albert Kihunrwa, ${ }^{3}$ and Balthazar Gumodoka ${ }^{3}$ \\ ${ }^{1}$ Department of Obstetrics and Gynaecology, University of Dodoma, College of Health Sciences, P.O. Box 395, Dodoma, Tanzania \\ ${ }^{2}$ Department of Internal Medicine, University of Dodoma, College of Health Sciences, P.O. Box 395, Dodoma, Tanzania \\ ${ }^{3}$ Department of Obstetrics \& Gynaecology, Catholic University of Health \& Allied Sciences, P.O. Box 1464, Mwanza, Tanzania
}

Correspondence should be addressed to Abdallah Mlwati; mlwati2000@gmail.com

Received 10 January 2017; Accepted 3 April 2017; Published 13 April 2017

Academic Editor: Alexandre Rodrigues Marra

Copyright (c) 2017 Athanase Lilungulu et al. This is an open access article distributed under the Creative Commons Attribution License, which permits unrestricted use, distribution, and reproduction in any medium, provided the original work is properly cited.

First described in 1925, giant condyloma acuminatum also known as Buschke-Löwenstein tumor (BLT) is a benign, slow-growing, locally destructive cauliflower-like lesion usually in the genital region. The disease is usually locally aggressive and destructive with a potential for malignant transformation. The causative organism is human papilloma virus. The most common risk factor is immunosuppression with HIV; however, any other cause of immunodeficiency can be a predisposing factor. We present a case of 33-year-old female patient, a known HIV patient on antiretroviral therapy for ten months. She presented with seven-month history of an abnormal growth in the genitalia that was progressive accompanied with foul smelling yellowish discharge and friable. Surgical excision was performed successfully. Pap smear of the excised tissue was negative. Despite being a rare condition, giant condyloma acuminatum is relatively common in HIV-infected patients.

\section{Introduction}

Anogenital warts, also known as condyloma acuminatum, are a common sexually transmitted disease among males and females caused by human papilloma virus (HPV) $[1,2]$. The lifetime risk of acquiring HPV is between $50 \%$ and $80 \%$ [3]. It is estimated that among individuals who contact HPV, 90\% will not develop genital warts, despite being able to transmit the disease [4]. Approximately $10 \%$ of individuals do not clear the infection and develop a persistent infection, with risk of developing genital warts [5]. Approximately $90 \%$ of genital wart cases are caused by low-risk HPV types (6 and 11) [1].

Giant condyloma acuminatum (GCA) is an extremely rare clinical form of genital warts, characterized by growth that extends into underlying dermal structures [6]. It is usually a benign, extensive cauliflower-like lesion commonly affecting the genitalia especially in immunosuppressed patients. Rarely, the lesion can extend to involve the anorectal region. GCA is usually nonresponsive to chemotherapy and radiotherapy. Local radical resection is mandatory for curative treatment [6].
We report a case of a 33-year-old HIV-infected patient on ART for ten months, who presented with seven-month history of progressive growth in the genitalia that was found to be GCA. Surgical resection was done successfully.

\section{Case Presentation}

We present a case of a 33-year-old female patient, Para 3+0, HIV-infected woman with baseline CD4-count of 30 cells/ul who has been on antiretroviral therapy (ART) for ten months prior to her visit. She presented to gynaecology clinic at Bugando Medical Centre, Mwanza, Tanzania, with seven-month history of progressive growths around genital region. The growths were of insidious onset, initially painless, although they later became painful. The lesion was initially noted on the edges of vaginal introitus; however they continued to spread to involve the perianal region. The growths were associated with foul smelling yellowish discharge. She has no history of receiving HPV vaccine.

On examination, there were huge multiple masses, friable, cauliflower-like in appearance, dark grayish-pink in 


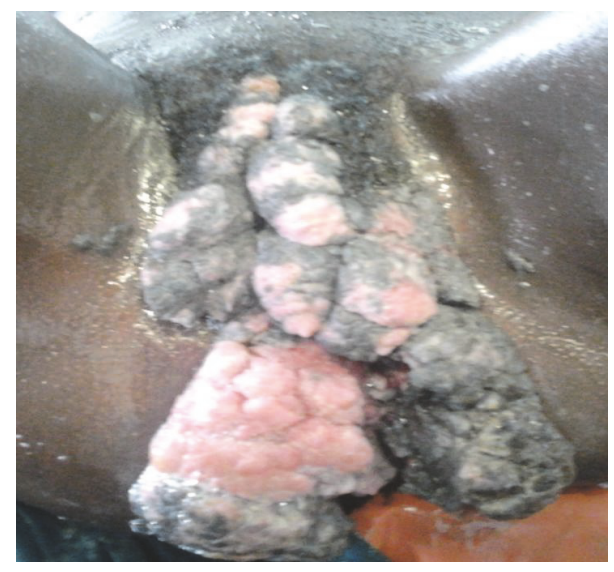

FIGURE 1: Giant condyloma acuminatum before surgical resection.

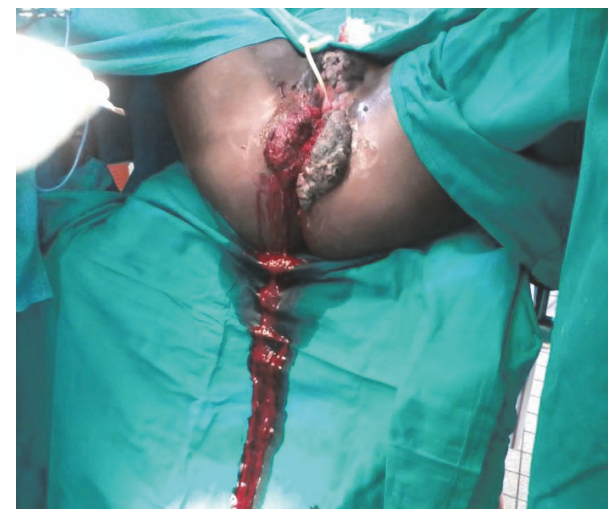

FIGURE 2: Giant condyloma acuminatum after surgical resection.

colour on her vulva involving both labia majora, extending anteriorly to the mons pubis and posteriorly to the perianal region, completely obliterating the urethral orifice, vaginal introitus, and anal opening (Figure 1). Masses were firm, edge growth, well-demarcated margins with rough surface. There were also some small satellite lesions on labia minora and the perianal region. There was also a foul smelling yellow vaginal discharge draining from multiple contoured margin areas on the masses.

There was no peripheral lymph node enlargement. The vitals were blood pressure $110 / 65 \mathrm{mmHg}$, pulse rate of 78 beats per minute, respiratory rate of 20 cycles per minute, and temperature of $37^{\circ} \mathrm{C}$. The diagnosis of GCA was reached. Due to the extensive nature of the lesions, surgical excision was planned and done successfully (Figure 2). The wounds healed by primary intention approximately one week after the procedure. Pap smear of the excised lesions was negative. Histological evaluation showed hyperkeratotic squamous epithelium underlying fibrous connective tissue stroma with nonspecific chronic inflammatory cells. There were no features of malignancy.

The patient was seen at one month and two months at which point she was doing fine, still on her ART with no recurrence of the vulval lesions. She was counseled on safe sex and other preventive measures for STIs. She was then lost to follow-up after six months of follow-up.

\section{Discussion}

Anogenital warts are the most common manifestation of genital HPV infection. Estimates show that among patients who contact HPV, only $10 \%$ develop genital warts [4], with HIV being the most significant predisposing risk factor. In rare occasions, anogenital warts may develop into extremely tumor masses, the so-called giant condyloma acuminata (GCA) or Buschke-Löwenstein tumors (BLT) [6]. These usually develop as cauliflower-like masses in the vulva although in rare cases like in our patient may extend to involve the perianal region. The tumor is slow-growing, highly destructive to contiguous tissue, and on rare occasions, it can metastasize. It is considered to be a regional variant of verrucous carcinoma [7].

GCA is usually a benign lesion with $30-56 \%$ chance of malignant transformation [8], being more common in men with a male to female ratio of $2.7-3.5: 1$. It is more common in men who are uncircumcised. The most common site for this tumor is on the glans penis; however, it can also be found on any anogenital mucosal surface like vulva, vagina, and rectum. Histologically, GCA exhibits features of pseudoepitheliomatous proliferation and local invasion by massive epidermal hyperplasia, hyperkeratosis, and parakeratosis; it is also markedly exophytic [9].

GCA is a rare tumor. It is even rare when in regions other than the penis like in our patient. Estimates show that GCA accounts for $5-24 \%$ of the penile cancers. The tumor has been shown to be associated with HPV subtypes 6 and 11 [10], the low-risk subtypes. Occasionally, however, it can be associated with the high risk subtypes (16 and 18). In one occasion the tumor was found to be associated with HPV subtype 54 .

GCA usually starts to grow as a keratotic plaque that expands slowly into a cauliflower-like mass. The growth takes longer in immunocompetent individuals. In immunosuppressed individuals, however, the growth is commonly more rapid [11]. The lesion may then ulcerate; typically the lesion may be associated with foul odor like in our case. Regional lymph node enlargement is common usually following secondary infection; our patient, however, did not have enlarged lymph nodes.

The treatment of choice for the management of GCA is considered wide surgical excision [6, 12]. Surgical excision alone has been shown to result into disease-free state in up to $46 \%$ of cases [13]. Oral and topical chemotherapeutic modalities can be used as adjuvant, to surgery. Some factors that need to be taken into account during treatment choice include the size and thickness of the lesions, anatomic site, associated HPV subtype, and the immune status. For giant lesions like in our patient, topical therapy alone is generally insufficient to control disease. No medication, however, can eradicate HPV infection. The role of radiation therapy remains controversial. The role of ART is not clearly defined. This patient had been on ART for about ten months without any improvement on her lesions. Other reports also show that the use of ART does not improve HPV-associated lesions [14]. 


\section{Conclusion}

Despite being a very rare manifestation, giant condyloma acuminatum of the vulva occurs, especially in immunosuppressed patients. Surgical excision remains the mainstay of treatment with adequate cure rate and limited recurrences. HPV screening should be done routinely to HIV-infected patients to increase the chances of early diagnosis and treatment.

\section{Consent}

A written informed consent was obtained from the patient for publication of this case report.

\section{Conflicts of Interest}

The authors declare that they have no conflicts of interest.

\section{Acknowledgments}

The authors acknowledge the help of the gynaecological ward nurses team and medical team together with theater operating room staffs who tirelessly assisted in the care of this patient and counseling.

\section{References}

[1] F. Aubin, J.-L. Prétet, A.-C. Jacquard et al., "Human papillomavirus genotype distribution in external acuminata condylomata: a large french national study (EDiTH IV)," Clinical Infectious Diseases, vol. 47, no. 5, pp. 610-615, 2008.

[2] H. Trottier and A. N. Burchell, "Epidemiology of mucosal human papillomavirus infection and associated diseases," Public Health Genomics, vol. 12, pp. 291-307, 2009.

[3] J. G. Baseman and L. A. Koutsky, “The epidemiology of human papillomavirus infections," Journal of Clinical Virology, vol. 32, supplement 1, pp. S16-S24, 2005.

[4] M. Stanley, "Immune responses to human papillomavirus," Vaccine, vol. 24, supplement 1, pp. S16-S22, 2006.

[5] A. B. Moscicki, M. Schiffman, A. Burchell, G. Albero, A. R. Giuliano, and M. T. Goodman, "Updating the natural history of human papillomavirus and anogenital cancers," Vaccine, vol. 30, supplement 5, pp. S24-S33, 2012.

[6] G. von Krogh, C. J. Lacey, G. Gross, R. Barrasso, and A. Schneider, "European course on HPV associated pathology: guidelines for primary care physicians for the diagnosis and management of anogenital warts," Sexually Transmitted Infections, vol. 76, pp. 162-168, 2000.

[7] R. A. Schwartz, "Verrucous carcinoma of the skin and mucosa," Journal of the American Academy of Dermatology, vol. 32, pp. 1-24, 1995.

[8] P. Bertram, K. H. Treutner, A. Rübben, S. Hauptmann, and V. Schumpelick, "Invasive squamous-cell carcinoma in giant anorectal condyloma (Buschke-Löwenstein tumor)," Langenbecks Archiv fur Chirurgie, vol. 380, no. 2, pp. 115-118, 1995.

[9] R. Knoblich and J. F. Failing, "Giant condyloma acuminatum (buschke-Löwenstein tumor) of the rectum," American Journal of Clinical Pathology, vol. 48, pp. 389-395, 1967.
[10] J. C. Braga, S. R. Nadal, M. Stiepcich, V. M. Framil, and H. Muller, "Buschke-Loewenstein tumor: identification of HPV type 6 and 11," Anais Brasileiros de Dermatologia, vol. 87, pp. 131134, 2012.

[11] P. V. Chin-Hong and J. M. Palefsky, "Human papillomavirus anogenital disease in HIV-infected individuals," Dermatologic Therapy, vol. 18, pp. 67-76, 2005.

[12] M. Tripoli, A. Cordova, F. Maggì, and F. Moschella, "Giant condylomata (Buschke-Löwenstein tumours): our case load in surgical treatment and review of the current therapies," European Review for Medical and Pharmacological Sciences, vol. 16, pp. 747-751, 2012.

[13] A. Renzi, P. Giordano, G. Renzi, V. Landolfi, A. del Genio, and E. G. Weiss, "Buschke-Lowenstein tumor successful treatment by surgical excision alone: a case report," Surgical Innovation, vol. 13, no. 1, pp. 69-72, 2006.

[14] I. Heard, J. M. Palefsky, and M. D. Kazatchkine, “The impact of HIV antiviral therapy on human papillomavirus (HPV) infections and HPV-related diseases," Antiviral Therapy, vol. 9, pp. 13-22, 2004. 


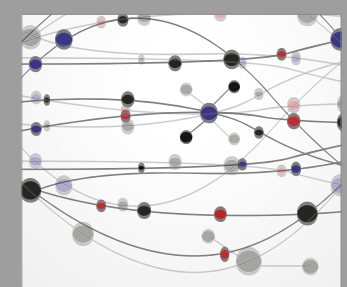

The Scientific World Journal
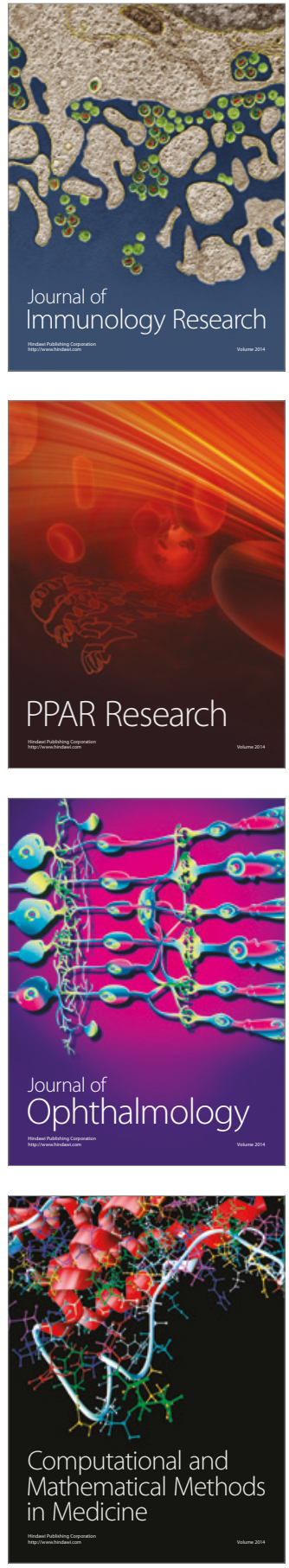

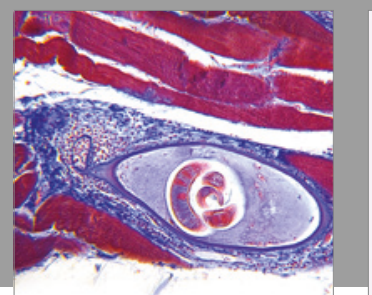

Gastroenterology Research and Practice
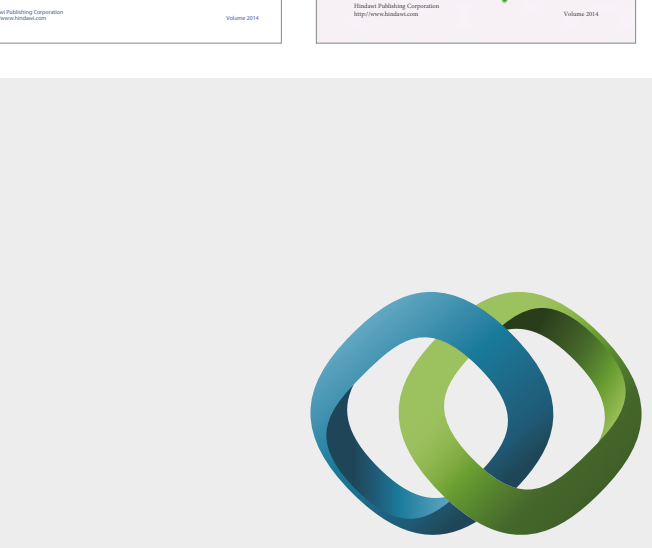

\section{Hindawi}

Submit your manuscripts at

https://www.hindawi.com
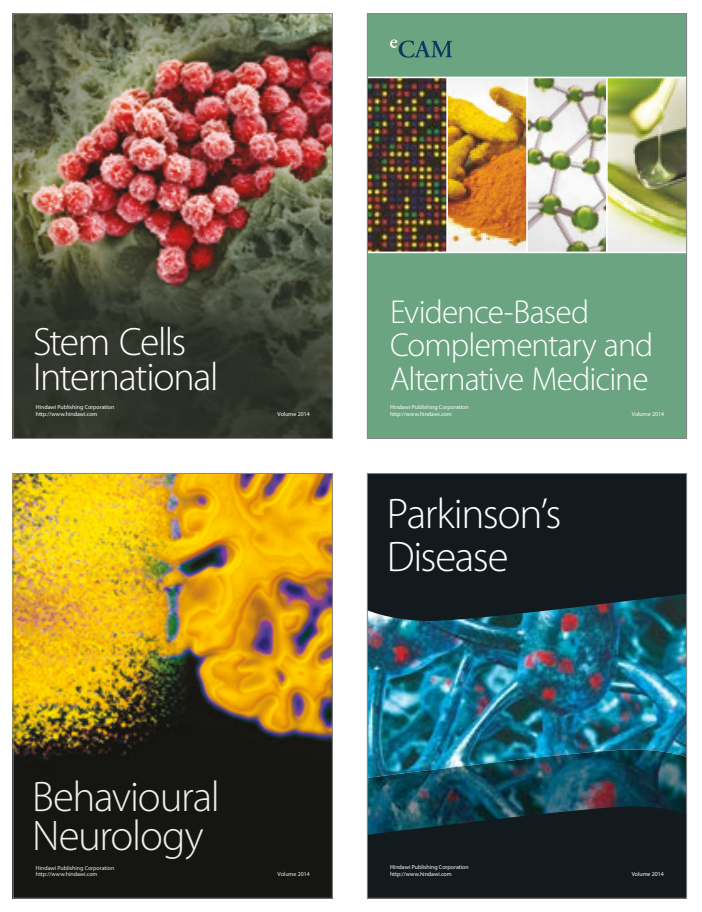
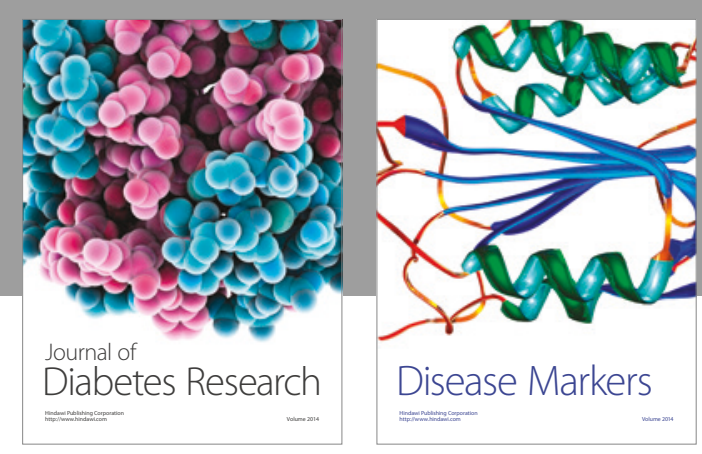

Disease Markers
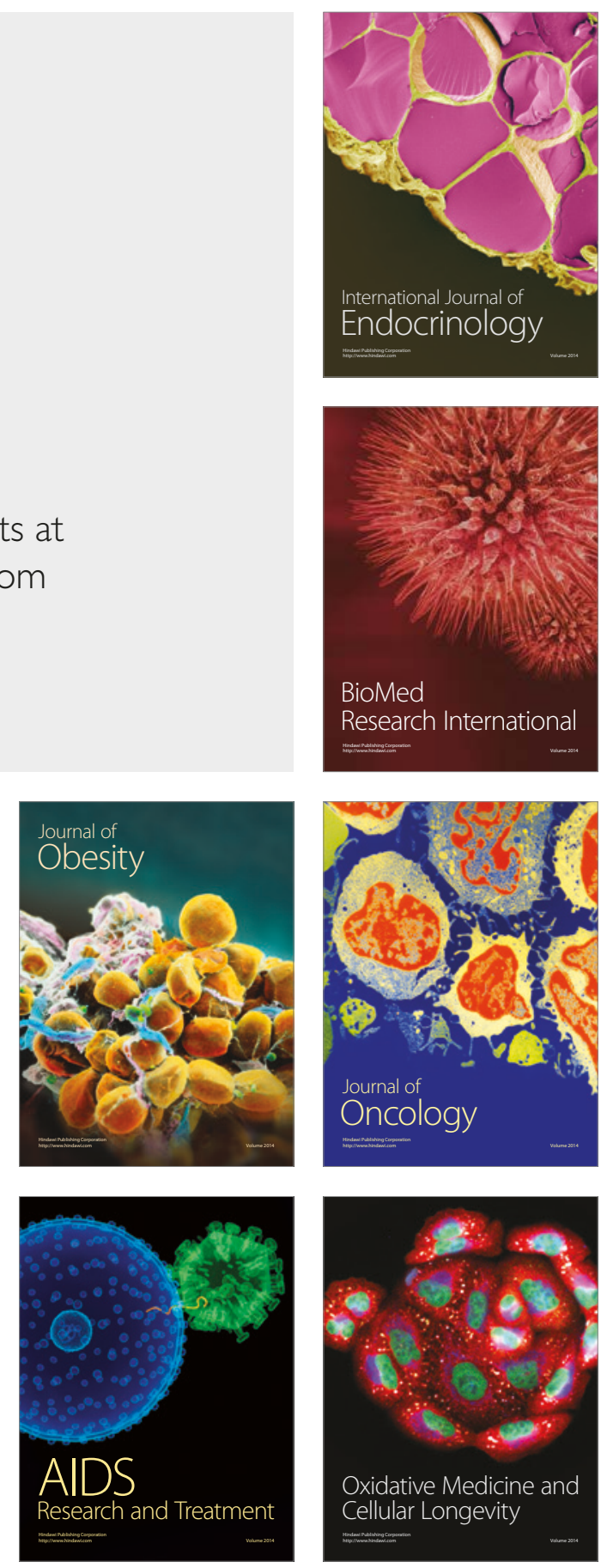